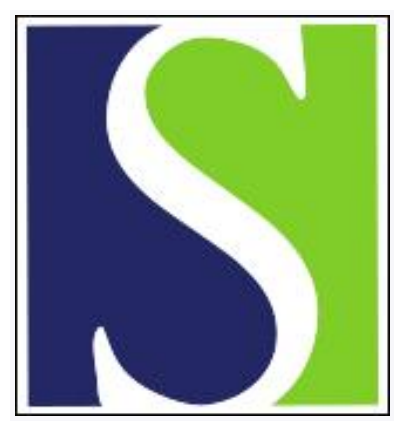

Scand J Work Environ Health 1988;14(3):153-160

https://doi.org/10.5271/sjweh.1937

Issue date: Jun 1988

A mortality study of vinyl chloride monomer workers employed in the United Kingdom in 1940-1974.

by Jones RD, Smith DM, Thomas PG

Affiliation: Epidemiology and Medical Statistics Unit, Health and Safety Executive, Bootle, Merseyside, Great Britain.

This article in PubMed: www.ncbi.nlm.nih.gov/pubmed/3393850

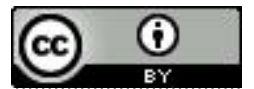




\title{
A mortality study of vinyl chloride monomer workers employed in the United Kingdom in 1940-1974
}

\author{
by Robert D Jones, FFOM, ${ }^{1}$ Deborah M Smith, BSc, ${ }^{2}$ Peter G Thomas, BSc ${ }^{1}$
}

\begin{abstract}
JONES RD, SMITH DM, THOMAS PG. A mortality study of vinyl chloride monomer workers employed in the United Kingdom in 1940-1974. Scand J Work Environ Health 14 (1988) 153-160. The mortality experience of 5498 male workers employed for at least one year during 1940-1974 in the vinyl chloride industry of the United Kingdom was followed through to 31 December 1984 . There was a significant excess of nonsecondary liver tumors with 11 deaths, of which seven were angiosarcomas. All the angiosarcoma deaths occurred in autoclave workers with a median latency of 25 years from date of first exposure. A strong healthy worker effect was seen. Other than that for liver cancer, no increased incidence of cancer deaths attributable to vinyl chloride monomer exposure was found. There was no evidence of increased mortality from chronic liver disease. The incidence of death from respiratory disease was low and was not affected by polyvinyl chloride dust exposure.
\end{abstract}

Key terms: angiosarcoma of the liver, cohort study, epidemiology, occupational exposure, vinyl chloride.

Following the early reports of an association between angiosarcoma of the liver and exposure to vinyl chloride monomer $(\mathrm{VCM})(5,8,14,17)$, the Employment Medical Advisory Service set up a mortality study of vinyl chloride workers in the United Kingdom; it was reported by Fox \& Collier (11). The purpose of the study was to establish the general picture of the mortality experience of workers engaged in the manufacture of polyvinyl chloride (PVC) in the United Kingdom and to relate this picture to various factors, including exposure to VCM. Two cases of angiosarcoma were identified, but the excess of mortality from liver cancer was not statistically significant when analyzed by categories defined in the International Classification of Diseases (ICD).

Since the association between VCM exposure and the development of angiosarcoma was established, various papers have suggested a carcinogenic effect for VCM in the induction of lung $(6,27)$ and brain $(4,7)$ cancers, melanoma (12), and malignancies of the hematopoietic system (28). However, despite the volume of literature now available on vinyl chloride exposure, it has yet to be established that this chemical causes an increase in malignancies at sites other than the liver.

Evidence of chronic liver disease, including hepatic fibrosis and portal hypertension, has been reported for VCM workers $(13,19,20,25)$. Noncirrhotic portal fibrosis, like angiosarcoma, is a prescribed disease for

1 Epidemiology and Medical Statistics Unit, Health and Safety Executive, Bootle, Merseyside, Great Britain.

2 Health Policy Analysis Unit, Yorkshire Regional Health Authority, Harrogate, Great Britain.

Reprint requests to: Dr RD Jones, Epidemiology and Medical Statistics Unit, Magdalen House, Stanley Precinct, Bootle, Merseyside, Great Britain L20 3QZ. this occupation in the United Kingdom under the Industrial Injury Provisions of the Social Security Act of 1975 (9). The role of chronic liver disease in the mortality pattern of these workers is not so clear (22).

Possible health effects of PVC dust have been the subject of a number of studies $(2,15,16,21,26)$, although some doubt remains as to whether the recorded changes in lung function and radiographic appearance are indicative of any increase in respiratory disease.

This paper describes a mortality analysis of British VCM workers that has primarily been based on the population reported on by Fox \& Collier (11). However, different criteria reducing the total cohort size, have been used for the entry of workers into the survey. The exposure categories have been based upon the more-detailed occupational information that is now available, and data on an extra 10 years of follow-up have been added.

\section{Subjects and methods}

\section{Study population}

A nominal roll was compiled from the personnel records of nine chemical plants manufacturing or polymerizing vinyl chloride. A prerequisite for entry into the cohort was employment for at least one year in a job or jobs that involved potential exposure to VCM for at least $25 \%$ of the workweek. Only individuals first employed in the period 1940-1974 were included. Persons were entered into the study at the time of completion of one year's employment in such an occupation. Identification details for each individual were sent to the Office of Population Censuses and Surveys, which flagged the records of the individual on the $\mathrm{Na}$ - 
Table 1. Exposure data by occupational category. $(\mathrm{VCM}=\mathrm{vinyl}$ chloride monomer, $\mathrm{PVC}=$ polyvinyl chloride)

\begin{tabular}{lrrr}
\hline Occupational category & \multicolumn{2}{c}{$\begin{array}{c}\text { VCM exposure estimate } \\
\text { (ppm) }\end{array}$} & $\begin{array}{c}\text { PVC dust } \\
\text { exposure } \\
\text { (mg/m }\end{array}$ \\
\cline { 2 - 3 } & $1940-1955$ & $1956-1974$ & \\
\hline $\begin{array}{l}\text { Autoclave operators } \\
\text { (group A) }\end{array}$ & $500-800$ & $150-500$ & $0.23-0.46$ \\
$\begin{array}{l}\text { Baggers and driers } \\
\begin{array}{l}\text { (group B) } \\
\text { Craftsmen }\end{array}\end{array}$ & $<400$ & $<40$ & $0.38-2.88$ \\
$\begin{array}{l}\text { (group C) } \\
\begin{array}{l}\text { Other workers } \\
\text { (group D) }\end{array}\end{array}$ & $240-440$ & $50-300$ & $0.52-0.84$ \\
\hline & $<100$ & $<100$ & $\leq 0.93$ \\
\hline
\end{tabular}

tional Health Service Central Register. Whenever an individual was found to have died, a copy of the death certificate duly coded to the appropriate ICD revision was sent to the investigators. The eighth revision of the ICD was used for deaths occurring to the end of 1978. Deaths occurring in 1979 to 1984 were coded to both the eighth and ninth revisions.

\section{Expected deaths}

Male mortality rates for England and Wales were calculated for selected ICD categories by five-year age groups for quinquennial periods of the study. The number of deaths expected for each ICD category was calculated by applying these rates to the person-years at risk in each five-year age group for the appropriate quinquennial period of the study. The person-years at risk were calculated from the date one year after first exposure to VCM up to the earliest of date of death, date of emigration, or 31 December 1984.

\section{Occupational exposure}

A list of 12 job titles was drawn up in conjunction with advice from the plants concerned, and each worker's employment history was recorded in accordance with this classification. Profiles of exposure to VCM and PVC dust were constructed for job titles from data supplied by company staff as part of an independent exercise prior to the analysis of any mortality data.

Reliable VCM exposure data were available for the more recent years, but for earlier periods estimates of exposure were produced with the use of any existing historical hygiene data and the recollection of employees, interpreted in the light of present knowledge, of the irritant and narcotic effects of VCM and their relationship to exposure levels. VCM exposure profiles were plotted and used for the determination of the exposure groups. The profile produced used much of the data previously presented by Barnes (1). The profile supported a further classification of the 12 job titles into autoclave workers (group A), baggers and driers (group B), craftsmen (group C), and other workers (group D).

Information on PVC dust levels was more sparse and only related to more recent exposures, but mea- surements showed the greatest exposures to have occurred among the baggers and driers (group B).

Table 1 shows the VCM exposure estimates for the occupational groups. These figures are not dissimilar to those reported by Ott et al (23). Because there was some movement between jobs, with a general tendency for workers to move from groups $A$ and $B$ to group $D$ (job movement among the craftsmen in group $C$ was much more limited) and because this movement tended to be from areas of high exposure to areas of low exposure, mortality by occupational exposure was analyzed from the population categorized as ever group $A$, ever group B never group A, ever group $C$ never group $\mathrm{A}$ or $\mathrm{B}$, and always group D.

Since 1974 exposure to VCM in the industry has been much more rigidly controlled. The levels fell almost immediately to less than $50 \mathrm{ppm}$, and even greater control has been achieved since. The present control limit for VCM is $3 \mathrm{ppm}$ annually with a maximum timeweighted average per workshift of $7 \mathrm{ppm}$. This level is many orders of magnitude less than the levels that existed for much of the study period, and therefore the present analysis was limited to persons who had worked in the industry prior to 1975 . All workers in the study have thus had the opportunity for at least 10 years of follow-up.

\section{Mortality analysis}

The use of ICD-categorized data is not ideal for studying rare tumors such as angiosarcoma, which would normally be expected to make only a tiny contribution to any particular ICD category. Even when all primary liver tumors are considered together, they account for less than $0.25 \%$ of deaths. Because the primary nature of the tumor is often not specifically mentioned on the death certificate, many of these deaths are not coded as primary liver cancer. In order to include these deaths, we found it necessary to include liver cancer deaths that were "not specified whether primary or secondary." By the aggregation of deaths coded to ICD categories 155.0 and 197.8 (eighth revision) and categories 155.0 and 155.2 (ninth revision), cases of liver cancer not specifically certified as metastatic were considered. Aggregated deaths from these causes have been referred to as "nonsecondary liver cancer."

Noncirrhotic fibrosis of the liver is not specifically mentioned in any ICD revision. It would presumably be coded to liver disease (ICD 570-573, eighth and ninth revisions). Within ICD categories 570-573 there are differences of classification between the eighth and ninth revisions, but it is very likely that noncirrhotic portal fibrosis would have been coded to 573 in the eighth revision and 571.9 or 573 in the ninth revision. The five certificates coded to an underlying cause between 570 and 573 were extracted and scrutinized. The underlying cause of death in all of these had been coded to 571. An expected figure was therefore calculated for 
ICD 571, which accounts, in the general population, for the vast majority of deaths from liver disease by either ICD revision.

The mortality analysis has been carried out with the OCMAP computer program (18). The standardized mortality ratios have been calculated in the normal manner, and the $95 \%$ confidence intervals for these ratios were calculated under the assumption that the observed number of deaths followed a Poisson distribution. The results are stated as significant when the standardized mortality ratio (SMR) 100 lies outside the $95 \%$ confidence interval $(95 \% \mathrm{CI})$.

\section{Results}

\section{General mortality pattern}

The number of workers meeting the criteria for entry into the study was 5560 men and 105 women. Because of the small number of female workers, detailed analysis was restricted to the male population. A total of 5498 men was traced $(98.9 \%)$, and 780 deaths were identified. Table 2 shows the observed $(\mathrm{O})$ and expected (E) deaths from major causes and other causes where there was a significant excess or deficit.

There were significant deficits in mortality from circulatory (O 381, E 429, SMR 89, $95 \%$ CI 80-09) and respiratory (O 76, E 105, SMR 72, $95 \%$ CI 57-90) diseases. These deficits contributed substantially to the overall significant deficit in mortality observed (O 780, E 894, SMR 87, 95 \% CI 81-94). There was a clearly significant overall excess of nonsecondary liver cancer (O 11, E 1.94, SMR 567, $95 \%$ CI 283-1 015).
Other causes of mortality for which there were significant deficits in mortality were diseases of the digestive system (O 14, E 23.9, SMR 59, $95 \%$ CI 32-98), peptic ulcer (O 2, E 7.5, SMR 27, 95 \% CI 3-96), and diseases of the genitourinary tract (O 5, E 11.9, SMR 42, $95 \%$ CI 14-98).

\section{Analysis of cancer by occupation}

Cancer mortality by occupation is shown in table 3 for malignancies which have been reported in excess in at least one population of VCM workers. There was an obvious excess of nonsecondary liver cancers among autoclave workers, but no statistically significant excesses of other cancers.

From table 1 it is clear that the greatest exposure to VCM was experienced by the autoclave workers,

Table 2. Mortality of the men traced. $(O=$ number of observed deaths, $\mathrm{E}=$ number of expected deaths, SMR = standardized mortality ratio, $95 \% \mathrm{Cl}=95 \%$ confidence interval)

\begin{tabular}{lrrrc}
\hline Cause & O & E & SMR & $95 \% \mathrm{Cl}$ \\
\hline Major causes of death & & & & \\
All causes & 780 & 894.2 & 87 & $81-94$ \\
All malignant neoplasms & 235 & 228.6 & 103 & $90-117$ \\
Stomach cancer & 26 & 23.9 & 108 & $71-159$ \\
Lung cancer & 81 & 92.1 & 88 & $70-109$ \\
Circulatory disease & 381 & 428.7 & 89 & $80-98$ \\
Ischemic heart disease & 276 & 287.8 & 96 & $85-108$ \\
Respiratory disease & 76 & 105.3 & 72 & $57-90$ \\
Bronchitis & 36 & 43.8 & 82 & $57-113$ \\
Accidents and suicides & 40 & 49.7 & 80 & $57-109$ \\
Other causes with a significant excess or deficit & & \\
Nonsecondary liver cancer & 11 & 1.9 & 567 & $283-1015$ \\
Disease of the digestive system & 14 & 23.9 & 59 & $32-98$ \\
Peptic ulcer & 2 & 7.5 & 27 & $3-96$ \\
Disease of the genitourinary & 5 & 11.9 & 42 & $14-98$ \\
system & 5 & & & \\
\hline
\end{tabular}

Table 3. Mortality from malignant diseases where association with exposure to vinyl chloride monomer was previously suggested..$^{a}(\mathrm{O}=$ number of observed deaths, $\mathrm{E}=$ number of expected deaths)

\begin{tabular}{|c|c|c|c|c|c|c|c|c|}
\hline \multirow{2}{*}{ Cause of death } & \multicolumn{2}{|c|}{$\begin{array}{l}\text { Autoclave } \\
\text { operators }\end{array}$} & \multicolumn{2}{|c|}{$\begin{array}{l}\text { Baggers and } \\
\text { driers }\end{array}$} & \multicolumn{2}{|c|}{ Craftsmen } & \multicolumn{2}{|c|}{ Other workers } \\
\hline & $\mathrm{O}$ & $E$ & o & $E$ & 0 & $E$ & 0 & $E$ \\
\hline All cancer & 41 & 43.3 & 20 & 21.8 & 20 & 23.2 & 154 & 139.7 \\
\hline \multicolumn{9}{|l|}{ Malignant neoplasm } \\
\hline Liver & 1 & 0.28 & - & 0.14 & - & 0.14 & 2 & 0.80 \\
\hline $\begin{array}{l}\text { Liver, not specified } \\
\text { whether primary or } \\
\text { secondary }\end{array}$ & 6 & $0.10^{*}$ & 1 & 0.05 & - & 0.06 & 1 & 0.36 \\
\hline Larynx & 1 & 0.42 & - & 0.20 & - & 0.22 & 3 & 1.37 \\
\hline Lung & 16 & 17.1 & 5 & 8.75 & 4 & 9.52 & 56 & 56.5 \\
\hline Malignant melanoma & - & 0.41 & - & 0.20 & - & 0.17 & 2 & 0.94 \\
\hline Brain & 1 & 1.42 & 1 & 0.74 & 1 & 0.62 & 1 & 3.35 \\
\hline $\begin{array}{l}\text { Lymphosarcoma and } \\
\text { reticulo cell sarcoma }\end{array}$ & 2 & 0.47 & - & 0.23 & - & 0.23 & 2 & 1.41 \\
\hline Other lymphoid tissue & - & 0.47 & - & 0.24 & - & 0.21 & 1 & 1.11 \\
\hline Lymphatic leukemia & - & 0.31 & 1 & 0.14 & - & 0.15 & 3 & 1.01 \\
\hline Thyroid & 1 & 0.08 & 1 & 0.04 & - & 0.04 & 0 & 0.26 \\
\hline Colon & - & 2.63 & 1 & 1.29 & 1 & 1.39 & 7 & 8.60 \\
\hline
\end{tabular}

a The workers were classified by the job held with the highest exposure to vinyl chloride monomer, ie, ever A, ever B, never $A$, etc, as described in the text.

* $P<0.5$. 
Table 4. Observed $(O)$ and expected (E) mortality for nonsecondary liver cancers by latency and cumulative exposure among autoclave workers (ie, workers exposed only as autoclave operators).

\begin{tabular}{|c|c|c|c|c|c|c|c|c|c|c|}
\hline \multirow{3}{*}{$\begin{array}{l}\text { Time since } \\
\text { first starting } \\
\text { job } \\
\text { (latency) }\end{array}$} & \multicolumn{10}{|c|}{ Length of exposure } \\
\hline & \multirow{2}{*}{$\frac{\leq 1}{0}$} & \multirow{2}{*}{$\frac{\text { year }}{E}$} & \multicolumn{2}{|c|}{$2-4$ years } & \multicolumn{2}{|c|}{$5-9$ years } & \multicolumn{2}{|c|}{$\geq 10$ years } & \multicolumn{2}{|c|}{ Total } \\
\hline & & & 0 & $E$ & 0 & $E$ & 0 & $E$ & 0 & $E$ \\
\hline $\begin{array}{l}\leq 9 \text { years } \\
10-19 \text { years } \\
\geq 20 \text { years }\end{array}$ & $\frac{-}{-}$ & $\begin{array}{l}0.03 \\
0.03 \\
0.03\end{array}$ & $\begin{array}{r}- \\
-\end{array}$ & $\begin{array}{l}0.03 \\
0.03 \\
0.0\end{array}$ & $\begin{array}{r}1 \\
1 \\
-\end{array}$ & $\begin{array}{l}0.04 \\
0.03 \\
0.01\end{array}$ & $\frac{-}{4}$ & $\begin{array}{l}0.00 \\
0.07 \\
0.08\end{array}$ & $\begin{array}{l}1 \\
2 \\
4\end{array}$ & $\begin{array}{l}0.10 \\
0.16^{*} \\
0.13^{*}\end{array}$ \\
\hline Total & - & 0.07 & 1 & 0.08 & 2 & 0.08 & 4 & 0.15 & 7 & $0.38^{*}$ \\
\hline
\end{tabular}

Table 5. Mortality from respiratory disease for baggers and driers and for craftsmen. ${ }^{a}(\mathrm{O}=$ number of deaths observed, $E=$ number of deaths expected)

\begin{tabular}{|c|c|c|c|c|}
\hline \multirow{2}{*}{ Cause of death } & \multicolumn{2}{|c|}{$\begin{array}{c}\text { Baggers and } \\
\text { driers }\end{array}$} & \multicolumn{2}{|c|}{ Craftsmen } \\
\hline & 0 & $E$ & 0 & $E$ \\
\hline Lung cancer & 9 & 15.4 & 4 & 9.5 \\
\hline $\begin{array}{l}\text { All nonmalignant } \\
\text { respiratory disease }\end{array}$ & $4^{*}$ & 12.7 & 8 & 9.8 \\
\hline Bronchitis & 1 & 5.0 & 4 & 4.1 \\
\hline
\end{tabular}

a See the paragraph relating to polyvinyl chloride dust exposure and disease for a definition of the groups. * $\mathrm{P}<0.5$.

craftsmen had had substantial exposure, but baggers, driers and "other" workers had had much lower exposures. The group of men who had ever worked on the autoclaves (highest exposure - group A) had a statistically significant excess of liver tumors coded as "tumors of the liver and intrahepatic ducts not specified as secondary tumors" (O 7, E 0.38, SMR 1842 , $95 \%$ CI 741-3 795). The same group did not show any statistically significant excess for any other malignant disease. Table 4 shows an analysis of observed and expected deaths from nonsecondary liver cancers in autoclave workers by length of exposure and latency. Four of the seven decedents were men with more than 10 years of cumulative exposure at a time more than 20 years after their first exposure to vinyl chloride. All seven deaths were due to angiosarcoma. The latency period between time of first exposure to VCM and death ranged from 8 to 33 years with a median latency of 25 years.

The analysis of other malignant diseases for which two or more deaths occurred revealed an excess of urinogenital cancer among workers with a low level of exposure (group D) (O 23, E 14.7, SMR 156, $95 \%$ CI 99-235), largely due to excess bladder and prostate cancer (O 19, E 11.7, SMR 163, $95 \%$ CI 98-254). The excess of bladder cancer that was seen in the population overall was confined to three associated factories at which a variety of chemicals was made $(\mathrm{O} 10$, E 4.3, SMR 233, $95 \%$ CI 112-429). The same three factories showed a significant excess mortality from urinogenital cancer (O 19, E 8.6, SMR 221, $95 \% \mathrm{Cl}$ 133-345).

\section{Vinyl chloride exposure and nonmalignant disease}

Nonmalignant liver disease (ICD 570-573) was responsible for five deaths, all of which had been coded to ICD 571 by the Office of Population Censuses and Surveys. For this disease category there was no excess of mortality in the population as a whole (O 5, E 4.9) although the autoclave workers did contribute two cases $(\mathrm{O} 2, \mathrm{E} 1.1)$, one of which had been certified as hepatic fibrosis and accepted by the coroner as a case of industrial disease. The remaining four deaths were due to cirrhosis of the liver. Death certificates for the 11 cases of nonsecondary liver cancer (which included the seven angiosarcomas found in the autoclave workers) gave no mention of hepatic fibrosis, although two (one hepatoma and one angiosarcoma) contained reference to cirrhosis.

\section{Polyvinyl chloride dust exposure and disease}

Baggers and driers (group B) were considered the high exposure group for PVC dust, craftsmen having less exposure and groups A and D the least. Table 5 shows the mortality from respiratory disease for the men who had ever been baggers or driers, regardless of previous or subsequent VCM or PVC exposure, and craftsmen who had never been autoclave workers or baggers or driers. The table shows that there was a nonsignificant deficit of malignant disease and a significant deficit of nonmalignant respiratory disease among the baggers and driers. The mortality for craftsmen showed no evidence of any significant excess of respiratory disease.

\section{Discussion}

This study reports the mortality experience of workers engaged in the manufacture and polymerization of vinyl chloride for the major chemical companies in the United Kingdom from 1940 on. In order to restrict the population to persons with definite occupational exposure and thereby prevent dilution of the cohort with substantial numbers of workers who had very small exposures, we have included only persons who have worked for more than one year in jobs judged to involve some exposure to VCM for at least $25 \%$ of the workshift. These selection criteria reduced the size of the cohort originally reported on by Fox \& Collier (11) from 7409 to 5498 . Restriction of recruitment to the period for which the previous report was written ensured a minimum possible follow-up period of 10 years. In addition to any considerations of latency, 
work conditions would have been very different in the post-1974 period with much lower exposures to VCM.

Objective hygiene data, along with estimates based on individuals' personal memory and judgement, showed that, while levels of exposure had fallen during the time period studied, substantial reductions had been particularly associated with the mid to late $1950 \mathrm{~s}$ and then again in the early 1970s. The hygiene data available indicated that autoclave workers had the highest exposure to VCM, baggers and driers the highest PVC dust exposure, and craftsmen intermediate exposure for both the monomer and the polymer.

In the absence of detailed information on individual exposure, the correlation of exposure and effect could have been attempted in a number of ways. After due consideration we decided that the analysis should be by occupation in accordance with the hygiene data. It is accepted that grouping the population in this way is a relatively crude method of assessing exposure and correlating this exposure with effect, and the accuracy of such a method depends upon the relevance of the groupings chosen and the precision of historical occupational data.

Another possible weakness of the study is that, while comparable mortality rates were available for the period in which over $80 \%$ of the deaths occurred, expected deaths for the period before the eighth ICD revision were calculated with the use of mortality data that were not directly comparable. This period would have accounted for over $25 \%$ of the expected mortality. The differences between the eighth and ninth revisions dictate the way in which the observed deaths have been categorized. Any bias introduced by attempts to define comparable data coded under different ICD revisions would operate differently for different diseases according to the changes made in the classification.

\section{Overall mortality}

The overall mortality of the subjects studied (table 2) shows a strong healthy worker effect, more obvious for respiratory than circulatory diseases. The fact that the effect is more evident for some occupational groups than for others may be a reflection of different physical demands of work activity in different jobs.

\section{Liver cancer}

There was an overall statistically significant excess of mortality from nonsecondary liver cancer (O 11, E 1.94 , SMR $567,95 \%$ CI 283-1 015), largely due to seven cases of angiosarcoma, six of which occurred at the same plant and all of which occurred in autoclave workers. No other nonsecondary liver tumors occurred among the autoclave workers, but these seven cases were sufficient to produce a huge excess for this disease category in this group (O 7, E 0.38, SMR 1842, $95 \%$ CI $741-3795)$. The results vividly demonstrate the association between VCM exposure and an in- creased risk of primary liver tumor, even though this oncogenic effect is probably limited to the induction of angiosarcoma. This was not the case at the time of Fox \& Collier's analysis when only two angiosarcoma deaths had occurred. Ten years of additional followup have produced sufficient deaths from angiosarcoma for nonsecondary liver tumors to be significantly in excess for the whole population; yet it must be realized that this excess is the result of seven angiosarcomas, all of which occurred in autoclave workers, and the remaining workers contribute little to the nonsecondary liver tumor deaths (O 4, E 1.58, SMR 253, $95 \%$ CI 69-648). This nonsignificant excess cannot be taken as evidence of an association between VCM and nonangiosarcoma primary liver tumors. If VCM does play a part in the genesis of other primary liver tumors, its effect is clearly far weaker than for angiosarcoma, and the power of this study is insufficient to permit further comment.

Mortality studies are dependent upon the accuracy of death certification. Subsequent classification of the information on the certificate is subject to coding as carried out by a nosologist within the constraints imposed by the ICD. Comparative mortality data are not therefore a completely accurate measure of disease incidence, even for fatal conditions. The smaller the true incidence of the disease, the more easily any measure of it will be affected by allocation of individual cases to a particular category. Because of co-existing recordings of angiosarcoma $(3,10)$, it was possible to check the results of this mortality analysis against the figure for cases of VCM-related angiosarcoma of the liver in the United Kingdom. Two cases of angiosarcoma were identified in our cohort, for which the underlying cause of death had not been classified to any code for liver cancer. One described as hemangioendothelioma of the liver was coded to ICD (eighth revision) 227 (benign hemangioma/lymphangioma). In the case of the other man, histological evidence of angiosarcoma was found, but no mention was made of it on the death certificate, even though a verdict of industrial disease was given. Both men had been autoclave workers.

\section{Lung cancer}

There was a nonsignificant deficit of lung cancer in the cohort overall. If VCM does have a carcinogenic effect on the lung, then, given the usual latency for occupational lung cancer, any excesses should be seen in the longer follow-up groups. Table 6 shows the results for different periods of follow-up. No clear evidence of any increased lung cancer risk emerges with longer periods of follow-up. Autoclave workers followed for 20 years or more show a nonstatistically significant excess of lung cancer (O 10, E 6.5, SMR 154, $95 \%$ CI 74-283), but a nonstatistically significant excess in such small numbers must be viewed with caution. Thus the results of the study do not demonstrate 
Table 6. Lung cancer by period of follow-up.

\begin{tabular}{|c|c|c|c|c|c|c|}
\hline \multirow{3}{*}{$\begin{array}{l}\text { Occupational } \\
\text { group a }\end{array}$} & \multicolumn{6}{|c|}{ Period of follow-up } \\
\hline & \multicolumn{2}{|c|}{$\leq 9$ years } & \multicolumn{2}{|c|}{$\begin{array}{l}10-19 \\
\text { years }\end{array}$} & \multicolumn{2}{|c|}{$\begin{array}{l}\geq 20 \text { years } \\
\text { after first } \\
\text { exposure }\end{array}$} \\
\hline & 0 & $E$ & 0 & $E$ & 0 & $E$ \\
\hline $\begin{array}{l}\text { Autoclave operators } \\
\text { Baggers and driers } \\
\text { Craftsmen } \\
\text { Other workers }\end{array}$ & $\frac{-1}{7}$ & $\begin{array}{r}3.5 \\
2.3 \\
2.1 \\
10.3\end{array}$ & $\begin{array}{r}6 \\
1 \\
2 \\
21\end{array}$ & $\begin{array}{r}7.1 \\
3.7 \\
3.8 \\
18.8\end{array}$ & $\begin{array}{r}10 \\
3 \\
2 \\
28\end{array}$ & $\begin{array}{r}6.5 \\
2.8 \\
3.7 \\
27.5\end{array}$ \\
\hline
\end{tabular}

a The workers were classified by the job held with the highest exposure to vinyl chloride monomer, ie, ever A, ever B, never A, etc, as described in the text.

any association between VCM exposure and lung cancer deaths.

For any study of this kind its power (ie, ability to demonstrate excess disease risks where they exist) will be far greater for common causes of death such as lung cancer than for uncommon tumors such as primary liver cancer. A negative result could therefore be taken as evidence that, if VCM had any etiologic role in the development of lung cancer, it must be small in comparison with that seen for angiosarcoma of the liver. It should be remembered, however, that lung cancer is a common tumor because of the high prevalence of smoking during the time of this study period. Without smoking, lung cancer would be a far more uncommon disease. If vinyl chloride exerted a carcinogenic effect on the respiratory system that was not synergystic with the carcinogenic effect of smoking, then such an effect would be masked by the commonality of smokinginduced tumors. Thus the power of the study to detect excess lung cancer is not the only consideration to be borne in mind when VCM is being assessed as a possible respiratory carcinogen.

\section{Brain cancer}

On the whole, the population showed no excess of brain cancer, and, because of the small numbers associated with the individual exposure categories, the results do not warrant further discussion. The exposure and latency details for the four cases included in the analysis are given in table 7 along with two cases that have occurred in the post-1974 starters. This study does not offer any anecdotal or statistical evidence for an association between brain cancer and VCM exposure.

\section{Lymphatic cancer}

Because of the close association between non-Hodgkins lymphoma and chronic lymphatic leukemia, it is pertinent to consider the diseases which span the three different ICD codings 200, 202, and 204 together. Two deaths coded to ICD 200 for autoclave operators were numerically in excess of the expected figure $(\mathrm{O} 2, \mathrm{E}$ 0.47 , SMR 426, $95 \%$ CI 52-1 537), but this value did not reach statistical significance. There was also a nonstatistically significant excess of lymphatic leukemia among the workers with low exposure (group D) (O 3, E 1.1, SMR 273, $95 \%$ CI 56-797). The problems of interpreting such small numbers are considerable. However, the evidence of this study alone cannot be considered suggestive of a causative role for VCM in the production of lymphatic cancer.

\section{Other cancers}

Although an association for VCM exposure and cancer of the colon has previously been commented upon (12, $24)$, this study provides no evidence of an excess of large bowel cancer in persons exposed to vinyl chloride.

In the population described in this study, only two deaths from malignant melanoma occurred. Both involved men from the low-exposure group (O 2, E 0.94, SMR 213, $95 \%$ CI 26-769). There was therefore, nothing in these results to support an association between VCM and the development of melanoma of the skin.

Two deaths from cancer of the thyroid occurred. One autoclave operator who worked in this job for one year died of thyroid cancer 11 years after his first exposure to vinyl chloride. The other case involved a man who was a bagger for 14 years and died some 23 years after first exposure. Although not as rare as angiosarcoma, cancer of the thyroid is still a very uncommon tumor in men (approximately 120 deaths per year and about double that number of male cancer registrations

Table 7. Occupational exposure data for the cases of brain cancer.

\begin{tabular}{|c|c|c|c|c|c|c|}
\hline $\begin{array}{l}\text { Case } \\
\text { number }\end{array}$ & $\begin{array}{l}\text { Age first } \\
\text { employed } \\
\text { (years) }\end{array}$ & $\begin{array}{l}\text { Occupational } \\
\text { category }\end{array}$ & $\begin{array}{l}\text { Period of } \\
\text { exposure } \\
\text { (years) }\end{array}$ & $\begin{array}{l}\text { Year of } \\
\text { death }\end{array}$ & $\begin{array}{l}\text { Latency } \\
\text { (years) }\end{array}$ & $\begin{array}{l}\text { Wording on } \\
\text { death certificate }\end{array}$ \\
\hline 1 & 36 & Autoclave worker & 13 & 1964 & 13 & Left parietal glioblastoma \\
\hline 2 & 22 & Bagger & 27 & 1982 & 28 & $\begin{array}{l}\text { Multicystic glioma of left } \\
\text { cerebral hemisphere }\end{array}$ \\
\hline 3 & 46 & Craftsman & 1 & 1977 & 3 & Cerebral glioma \\
\hline 4 & 30 & Miscellaneous, low & 4 & 1974 & 4 & "Liphoma of corpuscalosa" \\
\hline 5 & 47 & Fitter & 1 & 1984 & 6 & Malignant cerebellar cyst \\
\hline 6 & 23 & Autoclave worker & 1 & 1983 & 6 & $\begin{array}{l}\text { Frontal astrocytoma of the } \\
\text { brain }\end{array}$ \\
\hline
\end{tabular}


in England and Wales). While it is not possible to interpret the occurrence of these two cases as being due to VCM, they are described in detail because of a similar nonsignificant excess having been described in another study (12).

The significant excess of urinogenital cancers (largely bladder and prostate) limited to three factories was an unexpected finding. The facts that autoclave operators did not show such an excess, that it was heavily contributed to by low-exposure workers, and that it was confined to three particular factories make an association with VCM unlikely. Occupational exposure to other chemicals on such multiprocess sites must be considered. However, in a study in which so many comparisons have been drawn, the possibility of this being a chance finding must remain. A case-referent study of these cases is to be carried out in order to investigate other possible occupational explanations.

\section{Nonmalignant disease}

In addition to the well-known association between vinyl chloride and angiosarcoma of the liver, noncirrhotic periportal fibrosis and portal hypertension is a prescribed occupational disease in the United Kingdom under the Industrial Injuries Provisions of the Social Security Act 1975 (6). An analysis by underlying cause of death showed no evidence of an excess of nonmalignant liver disease, although one certificate included mention of hepatic fibrosis which was adjudged by the coroner to be an industrial disease.

Noncirrhotic periportal fibrosis in VCM workers has, of course, been described (25), and some of these workers have subsequently developed angiosarcoma of the liver. The certificates for one case of hepatoma and one of angiosarcoma mentioned cirrhosis, but this disease was not considered to be the underlying cause of death. Cases of periportal fibrosis among VCM workers are probably underreported in mortality studies because other pathological conditions, including subsequent development of angiosarcoma of the liver, are likely to be quoted as the underlying cause of death.

PVC dust exposure has been shown to produce radiographic changes and a reduction of the ratio of forced expiratory volume in $1 \mathrm{~s}$ to forced vital capacity, but the clinical significance of these changes is unclear. The workers deemed to be the most exposed to PVC dust in this study (table 5) had a deficit of mortality from respiratory disease; thus there is no evidence in this study to suggest a relationship between PVC exposure and increased mortality from respiratory disease. Respiratory disease is, of course, considerably affected by smoking habits. Little inference can therefore be drawn from such small numbers with smoking data unavailable.

To conclude, the overall mortality pattern of VCM workers in the United Kingdom shows a typical healthy worker effect associated with such cohort populations. These workers have a significant excess of primary liver tumor illustrating a link between the VCM exposure of autoclave workers and the development of angiosarcoma. There is little evidence of any relationship between other causes of mortality and VCM exposure.

\section{Acknowledgments}

The population studied was first reported on by Fox $\&$ Collier, and the collection and management of the data have been continued by various members of the Health and Safety Executive staff since that time. We wish to acknowledge the considerable help and cooperation that we have had from the companies concerned and, in particular, from Dr Paddle and Mr Irvine. The study would not have been possible without the help and work of the staff of the Office of Population Censuses and Surveys at Southport. Finally, we would like to thank Dr Carter for his support and comments, $\mathrm{Mr}$ Hodgson for his invaluable help, and Ms J Law for her patience in typing various drafts and tables.

\section{References}

1. Barnes AW. Vinyl chloride and the production of PVC. Proc R Soc Med 69 (1976) 277-281.

2. Baser ME, Tockman MS, Kennedy TP. Pulınonary function and respiratory symptoms in polyvinyl chloride fabrication workers. Am Rev Respir Dis 131 (1985) 203-208.

3. Baxter PJ, Anthony PP, MacSween RN, Scheuer PJ. Angiosarcoma of the liver: Annual occurrence and aetiology in Great Britain. Br J Ind Med 37 (1980) 213-221.

4. Beaumont JJ, Breslow NE. Power considerations in epidemiologic studies of vinyl chloride workers. Am J Epidemiol 114 (1980): 5, 725-734.

5. Bloch JB. Angiosarcoma of the liver following vinyl chloride exposure. J Am Med Assoc 229 (1974) 53-54.

6. Buffler PA, Wood S, Eifler C, Suarez L, Kilian DJ. Mortality experience of workers in a vinyl chloride monomer production plant. J Occup Med 21 (1979): 3, 195-203.

7. Cooper WC. Epidemiologic study of vinyl chloride workers: Mortality through December 31st 1972. Environ Health Perspect 41 (1981) 101-106.

8. Creech JL, Johnson M. Angiosarcoma of the liver in the manufacture of polyvinyl chloride. J Occup Med 16 (1974) $150-151$.

9. Department of Health and Social Security. Notes on the diagnosis of occupational diseases. Her Majesty's Stationery Office, London 1979.

10. Forman D, Bennet B. Exposure to vinyl chloride and angiosarcoma of the liver: A report of the register of cases. Br J Ind Med 42 (1985) 750-753.

11. Fox AJ, Collier PF. Mortality experience of workers exposed to vinyl chloride monomer in the manufacture of polyvinyl chloride in Great Britain. Br J Ind Med 34 (1977) $1-10$.

12. Heldaas SS, Langard SL, Andersen A. Incidence of cancer among vinyl chloride and polyvinyl chloride workers. Br J Ind Med 41 (1984) 25-30.

13. Jones DP, Smith PM. Progression of vinyl chloride induced hepatic fibrosis to angiosarcoma of the liver. $\mathrm{Br}$ 
J Ind Med 39 (1982): 3, 306-307.

14. Lee FI, Harry DS. Angiosarcoma of the liver in a vinyl chloride worker. Lancet 1 (1974) 1316-1318.

15. Lilis R, Anderson H, Miller A, Selikoff I. Pulmonary change among vinyl chloride polymerization workers. Chest 69 (1976): 2 suppl, 299-303.

16. Lloyd MH, Gauld S, Copland L, Soutar CA. Epidemiological study of lung function of workers at a factory manufacturing polyvinyl chloride. $\mathrm{Br} \mathrm{J}$ Ind Med 41 (1985): 3, 328-333.

17. Mack L, Creech JL, Whelan JG, Johnson MN. Liver damage and angiosarcoma in vinyl chloride workers. $J$ Am Med Assoc 230 (1974) 64-68.

18. Marsh GM, Preininger M. OCMAP: A user-orientated occupational cohort mortality analysis program. Am Stat 34 (1980) 245.

19. Marsteller HJ, Lelbach WK, Muller R, Gedigk P. Unusual splenomegalic liver disease as evidenced by peritoneoscopy and guided liver biopsy among polyvinyl chloride production workers. Ann NY Acad Sci 246 (1975) $95-134$.

20. Marsteller HJ, Lelbach WK, Muller R, Juhe S, Lange $\mathrm{CE}$, Rohner HG, Veltman G. Chronic toxic liver damage in workers of a PVC producing plant. Dtsch Med Wochenschr 98 (1973) 2311-2314.

21. Miller A, Teurstein AS, Cheung M, Selikoff IJ, Warshaw R. Changes in pulmonary function in workers ex- posed to vinyl chloride and polyvinyl chloride. Ann NY Acad Sci 246 (1975) 42-53.

22. Nicholson WJ, Henneberger PK, Seidman H. Occupational hazards in the VC-PVC industry in industrial hazards of plastic and synthetic elastomers. Liss, New York, NY 1984, pp 155-175.

23. Ott MG, Langner RR, Holder BB. Vinyl chloride exposure in a controlled industrial environment. Arch Environ Health 30 (1975) 333-339.

24. Salmon AG. Editorial: Vinyl Chloride: The evidence for human carcinogenicity in different target organs. $\mathrm{Br} \mathbf{J}$ Ind Med 42 (1985) 73-74.

25. Smith PM, Crossley IR, Williams DMJ. Portal hypertension in vinyl chloride monomer workers. Lancet 2 (1976) 602-604.

26. Soutar CA. Epidemiological study of respiratory disease in workers exposed to polyvinyl chloride dust. Thorax 35 (1980): suppl 9, 644-652.

27. Waxweiler RJ, Stringer W, Wagoner JK, Jones J, Falk $\mathrm{H}$, Carter C. Neoplastic risk among workers exposed to vinyl chloride. Ann NY Acad Sci 271 (1976) 40-48.

28. Weber H, Reinl W, Greiser E. German investigations on morbidity and mortality of workers exposed to vinyl chloride. Environ Health Perspect 41 (1981) 95-99.

Received for publication: 20 July 1987 